\title{
Correction to: What lifestyle factors predict depressive symptoms? A longitudinal assessment among permanent supportive housing residents
}

\author{
Esther J. Holmes ${ }^{1} \cdot$ Subhash Aryal ${ }^{2} \cdot$ Scott T. Walters ${ }^{1}$ \\ Published online: 27 July 2021 \\ (C) Springer-Verlag GmbH Germany, part of Springer Nature 2021
}

Correction to: Journal of Public Health: From Theory to Practice (2021)

https://doi.org/10.1007/s10389-021-01555-5

The original article contains an error. In the first sentence of the physical activity of the discussion section, "150 METs" should be corrected to "600 METs" per author request.

The original article has been corrected.

Publisher's note Springer Nature remains neutral with regard to jurisdictional claims in published maps and institutional affiliations.

The online version of the original article can be found at https://doi.org/ $10.1007 / \mathrm{s} 10389-021-01555-5$

Esther J. Holmes

esther.holmes@unthsc.edu

1 Department of Health Behavior and Health Systems, University of North Texas Health Science Center, 3500 Camp Bowie Blvd, Fort Worth, TX 76107, USA

2 Department of Biostatistics and Epidemiology, University of North Texas Health Science Center, 3500 Camp Bowie Blvd, Fort Worth, TX 76107, USA 